\title{
Electrocoagulation of the Effluents from Surfactant-Aided
}

\section{Soil-Remediation Processes}

\author{
R. Lopez-Vizcaíno, C. Sáez*, P. Cañizares, M.A. Rodrigo \\ Department of Chemical Engineering, Universidad de Castilla La Mancha, Enrique \\ Costa Building, Campus Universitario s/n, 13071 Ciudad Real, Spain
}

\begin{abstract}
The work described here concerns the electrochemical coagulation of effluents obtained in a surfactant-aided soil-remediation processes, in which phenanthrene was extracted from a clay soil using a sodium dodecyl sulphate solution as the solubilising fluid. The results show that the efficiency of the processes is largely influenced by the electrode materials employed in the electrocoagulation process and also by the initial $\mathrm{pH}$ of the treated effluents. Different cases have been studied, including synthetic effluents from soil-washing and electrokinetic soil-flushing. This technique is particularly effective in the treatment of the strongly acidic effluents arising from electrokinetic surfactant-aided soil-flushing of polluted soils using aluminium electrodes (anodes and cathodes). Under these conditions, in addition to a high level of pollution removal, this technology provides a significant reduction in the conductivity and partial neutralization of the effluent.
\end{abstract}

\section{Keywords}

Electrocoagulation, surfactant-aided, soil washing, soil flushing

*author to whom all correspondence should be addressed

email: cristina.saez@uclm.es; phone: 902204100 Fax: 902204130 


\section{INTRODUCTION}

The current problems associated with soil and groundwater contamination have led to significant progress in the technologies for soil decontamination. For the particular case of soils polluted with hydrophobic organic compounds (HOCs), the technologies based on the use of washing or flushing fluids are becoming increasingly important. These technologies allow the transfer of organic pollution contained in the soil to a liquid phase that can later be treated with an efficient wastewater treatment technology. These approaches are commonly known as surfactant-aided soil-remediation processes (SARS), although three different cases can be discerned depending on the way in which the pollutants are extracted from the soil. The first case corresponds to surfactant-aided soil washing processes (SASW) [1-4], which involve ex situ washing of soils with an aqueous surfactant solution with the aim of enhancing the water solubility of the HOCs and the formation of $\mathrm{O} / \mathrm{W}$ emulsions with micro-drops of HOC. The second case, surfactant-aided soil flushing (SASF), is based on dragging of pollutants through the soil by the movement of a flushing fluid. Two different technologies can be distinguished within this area: conventional soil flushing (SASCF) [5-10] and electrokinetic soil flushing (SASEF) [11-15]. The main difference between these approaches is the driving force, which in the first case is the pressure gradient between the injection site of the flushing fluid and the fluid extraction site, and in the second case is a voltage gradient between rows of electrodes located in electrolyte wells in the soil.

In all three treatments, the effluents produced had the same composition, i.e. the $\mathrm{O} / \mathrm{W}$ emulsion polluted with micro-drops of $\mathrm{HOC}$ and particles of soil. However, the 
physico-chemical properties of the effluents were different. In SASW and SASCF, the $\mathrm{pH}$, conductivity and certain other parameters are defined by the nature of the flushing fluid, while in the SASEF, the effluents obtained show a marked change in $\mathrm{pH}$ and a significant increase in conductivity. At this point, it is important to remark that the points of extraction of contaminants in electrokinetic flushing processes are the electrodes, in which electrolysis occurs independently of the nature of the flushing fluid. This fact has a great influence on the selection and performance of subsequent wastewater treatment.

Therefore, this type of effluent is quite complex and difficult to treat by conventional wastewater treatment methods. Several researchers have worked to develop methods suitable to treat these effluents and these approaches include advanced oxidation [1618], coagulation technologies [19,20], electrochemical oxidation [21-23] and even combinations of biological treatments [24-26] with some of the previously listed technologies. At present, one of the most relevant technologies for the treatment of $\mathrm{O} / \mathrm{W}$ emulsions is electrocoagulation or electrochemically assisted coagulation [27-29], although it is important to point out the lack of works focused on the use of this technology to treat SASW and SASEF effluents. This method involves destabilization of the micro-drops of organic materials by the action of a chemical reagent generated by electrodissolution of the anodic material (usually iron or aluminium) in an electrochemical cell. This process leads to the break-up of the emulsion and the formation of two phases that can be easily separated. The effectiveness of this technique depends on the coagulant species that are present in the system, and these species also depend on the $\mathrm{pH}$ of the matrix [30]. 
Taking this situation into account, the objective of the work described here was to study the electrocoagulation process for the treatment of effluents generated by SASW and SASEF of clay soil polluted with PAH. SASW and SASCF effluents are slightly alkaline while SASEF effluents are very acidic. In this study two partial objectives were set: firstly, to compare the effectiveness of the electrocoagulation process in the treatment of effluents arising from different remediation process and, secondly, to determine the best electrode materials in an electrocoagulation cell by studying three different electrode pairs: (anode/cathode) Aluminium/Aluminium, Iron/Aluminium, and Iron/Iron.

\section{EXPERIMENTAL}

In this work, kaolinite was selected as the model for a clay soil. This material is not reactive and it has a low hydraulic conductivity, low cation exchange capacity and zero organic content. The physico-chemical properties of this soil are shown in Table 1. Phenanthrene (PHE) (97\%) was selected as a model PAH and this compound was obtained from Merck. Sodium dodecyl sulphate (SDS) was used as a solubilising agent and this compound was obtained from Panreac. Sulphuric acid (96\%) was obtained from Panreac.

\subsection{Preparation of simulated soil.}

Samples of polluted soil were prepared by dissolving phenanthrene in acetone and then mixing this PHE/acetone solution with kaolinite. The spiked clay was aerated during one day to favour evaporation of the acetone and, in this way, the PHE was 
homogeneously distributed on the clay surface. This method has been described in the literature by different authors [22,23,31]. The resulting PHE concentration in the soil was around $500 \mathrm{mg} \mathrm{kg}^{-1}$ soil.

\subsection{Preparation of simulated effluent.}

The preparation of surfactant-aided soil-remediation process effluents (SASREs) was carried out in a stirred bench-scale tank operated in discontinuous mode. The tank

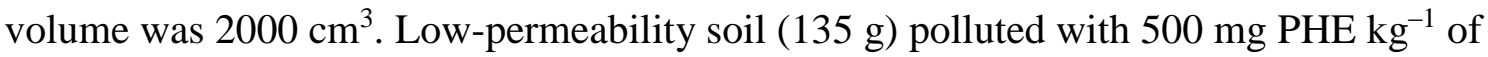

soil and $1800 \mathrm{~cm}^{3}$ of solubilising agent (containing deionised water and $10 \mathrm{~g} \mathrm{dm}^{-3}$ of surfactant) were mixed in the reactor for 6 hours at a stirring speed of $120 \mathrm{rpm}$ [32]. The same tank then acted as a settler (during 24 hours) to separate the soil from the effluent. These effluents consisted of aqueous mixtures of phenanthrene and surfactants with a very high COD. At this point, the $\mathrm{pH}$ was modified with sulphuric acid to produce the simulated SASEF effluent. The properties of effluents are shown in Table 2.

\subsection{Electrocoagulation of synthetic electrokinetic remediation wastewater.}

The electrocoagulation experiments were carried out in a bench-scale plant with a single-compartment electrochemical flow cell, as described in previous works [27-29]. Aluminium and iron electrodes were used as anodes and cathodes depending on the electrode configuration selected. Both electrodes were square in shape $\left(100 \mathrm{~cm}^{2}\right)$ and the electrode gap was $9 \mathrm{~mm}$. The electrical current was applied using a DC Power Supply (FA-376 PROMAX). The current flowing through the cell was measured with a KEITHLEY 2000 Digital Multimeter. The electrolyte was stored in a $5000 \mathrm{dm}^{3}$ glass tank stirred by an overhead stainless steel rod stirrer (HEIDOLPH RZR 2041) and 
thermostated by means of a water bath, which allowed the temperature to be maintained at the desired set point. The emulsion was circulated through the electrolytic cell by means of a peristaltic pump. The experiments were carried out under galvanostatic conditions.

\subsection{Analyses.}

The removal of pollution from effluents was monitored through the chemical oxygen demand (COD) using a HACH DR2000 analyzer. Zeta potential was also measured for the clarified liquid using a Zetasizer Nano ZS (Malvern, UK). The turbidity was measured on a 115 VELP SCIENTIFIC turbidimeter, using the Nephelometric Method [33]. This instrument measures the intensity of light scattered 90 degrees from the path of the incident light.

The phenanthrene concentration in the liquid phase was determined using an L-L extraction process. This process was carried out in bottles $\left(100 \mathrm{dm}^{3}\right)$ using hexane as the solvent (ratio PHE solution/solvent $=0.22 \mathrm{v} / \mathrm{v})$. Both phases were slowly stirred in an orbital shaker (100 rpm) during $5 \mathrm{~h}$ (operation time required to attain the steady state). In both cases, the concentration of phenanthrene in the resulting liquid extract phase was determined by UV-visible spectrophotometry (Shimadzu UV-1603). The characteristic absorbance peaks of phenanthrene in the UV-visible spectrum were at 346, 338 and $330 \mathrm{~nm}$. The absorbance at these three wavelengths was used to quantify the phenanthrene concentration. The standard deviation of this determination is less than $5 \%$. 


\section{RESULTS AND DISCUSSION}

\subsection{Dynamic response of the continuous electrocoagulation process.}

The surfactant-aided soil-remediation process effluent (SASRE) used in this work consisted of an emulsion of phenanthrene in water stabilized by the surfactants used in the soil washing process. In addition, this wastewater also contained particles of soil dragged in during the remediation process. Consequently, the SASREs consisted simultaneously of a colloidal suspension and an $\mathrm{O} / \mathrm{W}$ emulsion and, from the view point of electrocoagulation, two processes were carried out simultaneously: (i) break-up of the emulsion and (ii) destabilization of the colloidal suspension. Nevertheless, although these processes occurred simultaneously, they are independent of each other and different optimal conditions should be required for an efficient global electrocoagulation process.

In this respect, the supposed complexity of the system required a study into the typical performance of the process. Thus, the process performance is summarized in Figures 1 to 3 for the electrocoagulation of a SASRE with an electrochemical cell equipped with aluminium anodes and cathodes at three different initial $\mathrm{pHs}$. The first $\mathrm{pH}$ was slightly alkaline in an effort to reproduce the waste obtained in a typical soil washing process (SASW) (in fact, this was the raw effluent obtained in an actual soil washing process) and the second was acidic in an attempt to simulate the strongly acidic conditions found in the anodic wells during an electrokinetic soil flushing process (SASEF). At this point, it should be borne in mind that the negative charges of the phenanthrene-surfactant 
micro-drops favour their accumulation in the anodic wells in electrokinetic soil flushing processes, where the resulting wastewater could be easily collected and treated in an onsite electrocoagulation unit. The resulting wastewater was very acidic as a result of the water oxidation process, which is known to be the main electrochemical reaction that takes place on the surface of the anodes during an electrokinetic process with inert electrodes.

The turbidity and COD profiles during the three electrolyses are shown in Figure 1. Turbidity was used to monitor the removal of colloidal particles of clay dragged through during the washing of the soil. In all experiments, the general trend is the depletion of this parameter down to values close to zero. Although there is a significant removal at long reaction times, and results at this point are similar, the time-course of the turbidity during the three experiments is very different. In the strongly acidic media there is a continuous decrease in the turbidity, while in the other two cases there is an initial stage in which not a decrease but an increase is observed, possibly due to precipitation of coagulant species. This is followed by a second stage at higher electric current charge passed, in which turbidity decreases continuously down to the same value observed in the first case. This observation can be explained in terms of a different coagulation mechanism. In the first case, a very efficient charge-neutralization mechanism explains the rapid removal of turbidity. In the other two cases, however, a less efficient enmeshment coagulation mechanism provides an explanation for the experimental observations.

A different trend was observed for the break-up of the $\mathrm{O} / \mathrm{W}$ emulsion (arising from the action of the surfactant on the phenanthrene during the production of the SASRE) and 
for the consequent removal of organics. In all cases, there was a continuous decrease in the COD concentration, but the rate of removal depended strongly on the initial $\mathrm{pH}$. Under strongly acidic conditions, the COD decreased sharply down to values close to zero while under slightly alkaline conditions the process became less efficient as a slight decrease in COD was observed down to a value close to $60 \%$ of the initial COD. This finding suggests the existence of two coagulation mechanisms, with the acidic conditions consistent with a charge-neutralization mechanism and the alkaline conditions with a less efficient enmeshment coagulation mechanism, as previously suggested for the removal of the colloids in the same SASRE. The electrocoagulation at the intermediate $\mathrm{pH}$ shows a midway trend, with an initial sudden drop and a subsequent slight linear decrease. This result can be explained in terms of the mixed coagulation mechanisms previously described (enmeshment and neutralization). The zeta potential profile also lends support to this model (Figure 2). Strongly acidic media led to a rapid increase in zeta potential up to the isoelectric point, an observation that is characteristic of a neutralization mechanism. In the other cases, the zeta potential increased slightly with electric current charge but the isoelectric point was not reached. The latter observation is characteristic of an enmeshment mechanism.

The results described above show that the best $\mathrm{pH}$ conditions to treat SASRE effluents by electrocoagulation involve strongly acidic conditions, i.e. the conditions found in SASEF. In addition, this treatment has two advantages in cases where the initial $\mathrm{pH}$ is acidic: a significant reduction in conductivity and the neutralization of effluent $\mathrm{pH}$, thus making this treated wastewater more environmentally friendly (Figure 3). 


\subsection{Effect of the electrode material on the efficiency of the electrocoagulation process.}

One important aspect in the study of the electrocoagulation of SASRE is to clarify the role of the electrode material. Although iron and aluminium electrodes produce trimetallic cations during their electrochemical dissolution, the resulting speciation [34] is very different and one would expect the coagulation mechanisms to differ when the coagulants interact with pollutants. In addition, the effect of the $\mathrm{pH}$ on the chemical dissolution of aluminium is very important, and under alkaline $\mathrm{pH}$ values a significant concentration of aluminium is observed even when it is employed as a cathode in an electrocoagulation cell $[35,36]$. The highly alkaline $\mathrm{pHs}$ obtained close to the cathode surface (due to water reduction) promotes this process. This effect is not significant for iron, which is known to behave as an inert cathode material in electrocoagulation processes.

In order to assess this influence, several electrocoagulation experiments were carried out using three different electrode combinations in an effort to elucidate the effect on the removal of COD and turbidity of each material as the anode and as the cathode. The results obtained are summarized in figures 4 to 6 . In these figures one can see the ratio between steady state concentration attained in all of these electrolyses and the initial concentration of pollutant.

The effect on the turbidity removal is represented in Figure 4. It can be observed that iron had a negative effect on the results as compared with aluminium, and the best 
results were found when the anode and the cathode were made of aluminium and, in particular, when a very low $\mathrm{pH}$ was maintained during the experiment. This finding suggests that charge neutralization mechanisms (i.e. those promoted under these conditions) encourage the removal of the drawn soil whereas enmeshment to grow precipitates, which is the most important mechanism for iron, is not a good choice in this application, even in combination with aluminium (used as a cathode). This situation was clearly explained in previous publications by our group [37,38], in which the electrolyses of kaolin suspensions with both electrodes were studied in synthetic wastewaters and where the different mechanisms involved in the removal of colloids were demonstrated.

The COD removal is represented in Figure 5. Once again, the cell equipped with the aluminium anode and cathode gave the best results and the $\mathrm{pH}$ was a critical parameter, with the process being very efficient under very acidic conditions. This means that electrocoagulation could be a reference technology in the treatment of effluent from SASEF, because the SASRE is collected in the electrolyte wells at low $\mathrm{pH}$ and, in particular, in the anolyte wells (where negatively charged surfactant micro-drops are collected) the $\mathrm{pH}$ is extremely acidic. In this case, the combined effect of iron and aluminium dissolution does not improve the process and even has a detrimental effect on the separation results. Hence enmeshment mechanisms are not beneficial for this process.

The last important parameter to consider when comparing the influence of the different electrode materials on the efficiency of the electrocoagulation process is the effect on the conductivity of the electrochemical dosage of reagents. This parameter is 
represented in Figure 6 for the experiments reported. An increase in the conductivity is frequently observed in coagulation processes. However, one of the most important advantages of electrocoagulation is the decrease in the conductivity usually obtained during the electrochemical dosing of the reagent. This phenomenon is clearly observed Figure 6, where an increase in the conductivity is observed only in the experiments at slightly alkaline $\mathrm{pH}$ while the experiments at acidic $\mathrm{pH}$ show a significant decrease in this parameter. This finding is important because the quality of the treated waste depends not only on the removal of pollutants but also on a low conductivity. In addition, in this case the $\mathrm{pH}$ seems to make an important contribution as the decrease in conductivity is more marked for strongly acidic pHs. Once again, the electrode pair $\mathrm{Al} / \mathrm{Al}$ gave the best removal results and, hence, this combination must be recommended for the treatment of effluents arising from SASEF.

The results described above allow us to affirm that electrocoagulation with aluminium electrodes is a suitable and effective technique to treat acidic effluents from SASEF of polluted soil with hydrophobic organic compounds. Finally, the concentration of PHE and a sequence of pictures of the treatment are shown in Figures 7 and 8. As can be

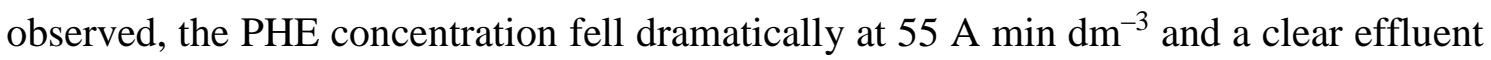
was obtained. Therefore, these results show that the treated wastewater is completely free of contamination from particles in suspension, surfactant and PHE.

\section{CONCLUSIONS}

Electrochemical coagulation can be successfully used to treat the effluents from a surfactant-aided soil-remediation process in which phenanthrene is extracted with a 
sodium dodecyl sulphate solution as the solubilising fluid. The efficiency of the process is largely influenced by the electrode materials employed in the electrocoagulation process and also by the initial $\mathrm{pH}$ of effluents. This technique is particularly effective for the treatment of strongly acidic effluents arising from SASEF of soil polluted with hydrophobic organic compounds and using aluminium electrodes (anodes and cathodes). Under these conditions, in addition to a high level of pollution removal, this technology leads to a significant reduction in the conductivity and partial neutralization of the effluent.

\section{Acknowledgements}

Financial support from the Spanish government through project CTM201018833/TECNO is gratefully acknowledged. 


\section{REFERENCES}

[1] K. Elgh-Dalgren, Z. Arwidsson, A. Camdzija, R. Sjöberg, V. Ribé, S. Waara, B. Allard, T. von Kronhelm, P.A.W. van Hees, Laboratory and pilot scale soil washing of $\mathrm{PAH}$ and arsenic from a wood preservation site: Changes in concentration and toxicity. J. Hazard. Mater. 172 (2009) 1033-1040.

[2] C.K. Ahn, Y.M. Kim, S.H. Woo, J.M. Park, Soil washing using various nonionic surfactants and their recovery by selective adsorption with activated carbon. J. Hazard. Mater. 154 (2008) 153-160.

[3] A. Petitgirard, M. Djehiche, J. Persello, P. Fievet, N. Fatin-Rouge, PAH contaminated soil remediation by reusing an aqueous solution of cyclodextrins. Chemosphere, 75 (2009) 714-718.

[4] W. Chu, K.H. Chan, The mechanism of the surfactant-aided soil washing system for hydrophobic and partial hydrophobic organics. Sci. Total Environ. 307 (2003) 83-92.

[5] M. Svab, M. Kubal, M. Müllerova, R. Raschman, Soil flushing by surfactant solution: Pilot-scale demonstration of complete technology. J. Hazard. Mater. 163 (2009) 410-417.

[6] A. Navarro, F. Martínez, The use of soil-flushing to remediate metal contamination in a smelting slag dumping area: Column and pilot-scale experiments, Eng. Geol. 115 (2010) 16-27.

[7] M. Lee, H. Kang, W. Do, Application of nonionic surfactant-enhanced in situ flushing to a diesel contaminated site, Water Res. 39 (2005) 139-146. 
[8] J-Y. Kim, S-B. Shim, J-K. Shim, Comparison of amphiphilic polyurethane nanoparticles to nonionic surfactants for flushing phenanthrene from soil, J. Hazard. Mater. 116 (2004) 205-212.

[9] M. Liu, D. Roy, G. Wang, Reactions and transport modeling of surfactant and anthracene in the soil flushing process, Waste Manage. 15 (1995) 423-432.

[10] S-K. Park, A.R. Bielefeldt, Non-ionic surfactant flushing of pentachlorophenol from NAPL-contaminated soil, Water Res. 39 (2005) 1388-1396.

[11] R.E. Saichek, K.R. Reddy, Electrokinetically Enhanced Remediation of Hydrophobic Organic Compounds in Soils: A Review. Environ. Sci. and Technol. 35 (2005) 115-192.

[12] J. Virkutyte, M. Sillanpää, P. Latostenmaa, Eletrokinetic soil remediationcritical overview, Sci. Total Environ. 289 (2002) 97-121.

[13] M.M. Page, C.L. Page, A review of electroremediation of contaminated soils, J. Environ. Eng. 128 (2002) 208-219.

[14] G-N. Kim, Y-H. Jung, J-J. Lee, J-K Moon, C-H. Jung, Development of electrokinetic-flushing technology for the remediation of contaminated soil around nuclear facilities, J. Ind. Eng. Chem. 14 (2008) 732-738.

[15] G-N. Kim, Y-H. Jung, J-J. Lee, J-K. Moon, C-H. Jung, An analysis of a flushing effect on the electrokinetic-flushing removal of cobalt and cesium from a soil around decommissioning site, Sep. Purif. Technol. 63 (2008) 116-121.

[16] V. Flotron, C. Delteil, Y. Padellec, V. Camel, Removal of sorbed polycyclic aromatic hydrocarbons from soil, sludge and sediment samples using the Fenton's reagent process. Chemosphere 59 (2005) 1427-1437. 
[17] J. Rivas, O. Gimeno, R.G. de la Calle, J.R. Portela, E. Martínez de la Ossa, Remediation of PAH spiked soils: Concentrated $\mathrm{H}_{2} \mathrm{O}_{2}$ treatment/continuous hot water extraction-oxidation, J. Hazard. Mater. 168 (2009) 1359-1365.

[18] A. Kornmüller, U. Wiesmann, Ozonation of polycyclic aromatic hydrocarbons in oil/water-emulsions: mass transfer and reaction kinetics, Water Res. 37 (2003) 1023-1032.

[19] T. Chatterjee, S. Chatterjee, D.S. Lee, M.W. Lee, S.H. Woo, Coagulation of soil suspensions containing nonionic or anionic surfactants using chitosan, polyacrylamide, and polyaluminium chloride, Chemosphere 75 (2009) 13071314.

[20] E. Önder, A.S. Koparal, Ü.B. Öğ̈̈tveren, An alternative method for the removal of surfactants from water: Electrochemical coagulation, Sep. Purif. Technol. 52 (2007) 527-532.

[21] C. Sáez, R. López-Vizcaíno, P. Cañizares, M.A. Rodrigo, ConductiveDiamond Electrochemical Oxidation of Surfactant-Aided Soil-Washing Effluents, Ind. Eng. Chem. Res. 49 (2010) 9631-9635.

[22] M.T. Alcántara, J. Gómez, M. Pazos, M.A. Sanromán, PAHs soil decontamination in two steps: Desorption and electrochemical treatment, J. Hazard. Mater. 166 (2009) 462-468.

[23] M.T. Alcántara, J. Gómez, M. Pazos, M.A. Sanromán, Combined treatment of PAHs contaminated soils using the sequence extraction with surfactant-electrochemical degradation, Chemosphere 70 (2008) 1438-1444.

[24] L-H. Tran, P. Drogui, G. Mercier, J-F. Blais, Coupling extractionflotation with surfactant and electrochemical degradation for the treatment of PAH contaminated hazardous wastes, J. Hazard. Mater. 170 (2009) 1218-1226. 

anaerobic digestion and ozonation to remove PAH from urban sludge, Process Biochem. 40 (2005) 3244-3250.

[26] P. Haapea, T. Tuhkanen, Integrated treatment of PAH contaminated soil by soil washing, ozonation and biological treatment, J. Hazard. Mater. 136 (2006) 244-250.

[27] P. Cañizares, F. Martínez, J. Lobato, M.A. Rodrigo, Break-up of Oil-inWater Emulsions by electrochemical techniques, J. Hazard. Mater. 145 (2007) $233-240$. P. Cañizares, F. Martínez, C. Jiménez, J. Lobato, M.A. Rodrigo, Coagulation and electrocoagulation of wastes polluted with dyes, Environ. Sci. and Technol. 40 (2006) 6418-6424.

P. Cañizares, F. Martínez, C. Jiménez, C. Sáez, M.A. Rodrigo,

Coagulation and electrocoagulation of oil-in-water emulsions, J. Hazard. Mater. 151 (2007) 44-51.

[30] J.M. Duan, J. Gregory, Coagulation by hydrolysing metal salts, Adv. Colloid Interface Sci. 100 (2003) 475-502.

[31] J-Y. Park, H-H. Lee, S-J. Kim, Y-J. Lee, J-W. Yang, Surfactantenhanced electrokinetic removal of phenanthrene from kaolinite, J. Hazard. Mater. 140 (2007) 230-236.

[32] M-C. Chang, C-R. Huang, H-Y. Shu, Effects of surfactants on extraction of phenanthrene in spiked sand, Chemosphere, 41 (2000) 1295-1300.

APHA, AWWA, WPCF. Standard Methods for the Examination of Water and Wastewater, 20th ed.; Clesceri, L.S., Greenberg, A.E., Eaton, A.D., 
Franson, M.A.H., Eds.; American Public Health Association: Washington, DC, 1989.

[34] P. Cañizares, F. Martínez, C. Jiménez, J. Lobato, M.A. Rodrigo, Comparison of the aluminum speciation in chemical and electrochemical dosing processes, Ind. Eng. Chem. Res. 45 (2006) 8749-8756.

[35] P. Cañizares, C. Jiménez, F. Martínez, M.A. Rodrigo, C. Sáez, The pH as a key parameter in the choice between coagulation and electrocoagulation for the treatment of wastewaters, J. Hazard. Mater. 163 (2009) 158-164.

[36] P. Cañizares, M. Carmona, J. Lobato, F. Martínez, M.A. Rodrigo, Electrodissolution of aluminum electrodes in electrocoagulation processes, Ind. Eng. Chem. Res. 44 (2005) 4178-4185.

[37] P. Cañizares, C. Jiménez, F. Martínez, C. Sáez, M.A. Rodrigo, Study of the electrocoagulation process using aluminum and iron electrodes, Ind. Eng. Chem. Res. 46 (2007) 6189-6195.

[38] P. Cañizares, F. Martínez, C. Jiménez, J. Lobato, M.A. Rodrigo, Coagulation and electrocoagulation of wastes polluted with colloids, Sep. Sci. Technol. 42 (2007) 2157-2175. 


\section{FIGURE CAPTIONS}

Figure 1. Turbidity (a) and COD (b) profiles with electric charge passed (dynamic responses) observed during several electrochemical coagulation experiments under acidic and alkaline conditions. Temperature: $25^{\circ} \mathrm{C}$; Current density:

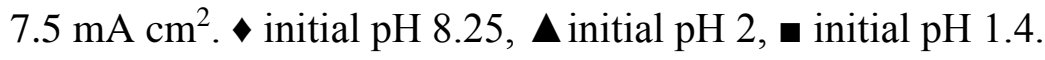

Figure 2. Zeta potential profile with electric charge passed (dynamic responses) observed during several electrochemical coagulation experiments under acidic and alkaline conditions. Temperature: $25^{\circ} \mathrm{C}$; Current density: $7.5 \mathrm{~mA}$ $\mathrm{cm}^{2}$. initial pH 8.25, $\mathbf{\Delta}$ initial $\mathrm{pH} 2$, $\mathbf{a}$ initial $\mathrm{pH} 1.4$.

Figure 3. Conductivity (a) and $\mathrm{pH}$ (b) profiles with electric charge passed (dynamic responses) observed during several electrochemical coagulation experiments under acidic and alkaline conditions. Temperature: $25^{\circ} \mathrm{C}$; Current density:

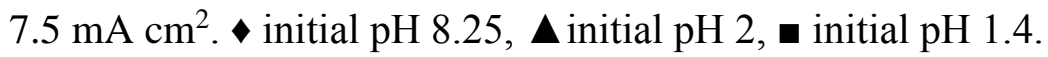

Figure 4. Normalized turbidity observed during different electrochemical coagulation experiments under acidic and alkaline conditions. Temperature: $25{ }^{\circ} \mathrm{C}$; Electric charge: $200 \mathrm{~A} \mathrm{~min} \mathrm{dm}^{-3}$, Current density: $7.5 \mathrm{~mA} \mathrm{~cm}{ }^{2} . \square \mathrm{Al} / \mathrm{Al}$, $\square \mathrm{Fe} / \mathrm{Fe}, \square \mathrm{Fe} / \mathrm{Al}$; (Anode/Cathode).

Figure 5. Normalized COD observed during different electrochemical coagulation experiments under acidic and alkaline conditions. Temperature: $25{ }^{\circ} \mathrm{C}$; Electric charge: $200 \mathrm{~A} \mathrm{~min} \mathrm{dm}^{-3}$, Current density: $7.5 \mathrm{~mA} \mathrm{~cm}{ }^{2}$. $\mathrm{Al} / \mathrm{Al}$, $\square \mathrm{Fe} / \mathrm{Fe}, \square \mathrm{Fe} / \mathrm{Al}$; (Anode/Cathode).

Figure 6. Normalized Conductivity observed during different electrochemical coagulation experiments under acidic and alkaline conditions. Temperature: $25{ }^{\circ} \mathrm{C}$, Electric charge: $200 \mathrm{~A}$ min $\mathrm{dm}^{-3}$, Current density: $7.5 \mathrm{~mA} \mathrm{~cm}$. $\mathrm{Al} / \mathrm{Al}, \square \mathrm{Fe} / \mathrm{Fe}, \square \mathrm{Fe} / \mathrm{Al} ;($ Anode/Cathode).

Figure 7. Phenanthrene concentration profile with electric charge passed (dynamic responses) observed during electrochemical coagulation experiment under 
acidic conditions. Temperature: $25^{\circ} \mathrm{C}$; Current density: $7.5 \mathrm{~mA} \mathrm{~cm}{ }^{2}$. Initial pH: 1.4 .

Figure 8. Photographs of samples observed during electrochemical coagulation experiments with aluminium under acidic conditions. Temperature: $25{ }^{\circ} \mathrm{C}$;

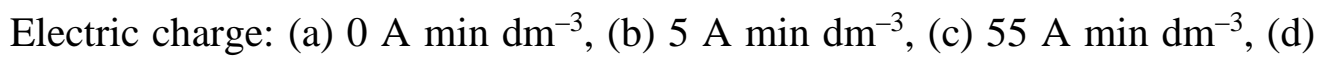
$130 \mathrm{~A}$ min $\mathrm{dm}^{-3}$. Current density: $7.5 \mathrm{~mA} \mathrm{~cm}{ }^{2}$. Initial pH 1.4 . 
Table 1. Properties of kaolinite.

\begin{tabular}{lr|lr}
\hline \multicolumn{2}{c|}{ Mineralogy } & \multicolumn{2}{c}{ Particle size distribution (\%) } \\
\hline & & Gravel & 0 \\
$\mathrm{Fe}_{2} \mathrm{O}_{3}$ & $0,58 \%$ & Sand & 4 \\
$\mathrm{TiO}_{2}$ & $0,27 \%$ & Silt & 18 \\
$\mathrm{CaO}$ & $0,10 \%$ & Clay & 78 \\
\cline { 2 - 2 } & $0,75 \%$ & Specific gravity & 2,6 \\
$\mathrm{~K}_{2} \mathrm{SiO}$ & $52,35 \%$ & Hydraulic conductivity (cm/s) & $1 \times 10^{-8}$ \\
$\mathrm{Al}_{2} \mathrm{O}_{3}$ & $34,50 \%$ & Organic content (\%) & 0 \\
Others & $11,42 \%$ & pH & 4,9 \\
\hline
\end{tabular}

Table 2. Properties of surfactant-aided soil-remediation effluents used in this work.

\begin{tabular}{l|c|c}
\hline \multicolumn{1}{c|}{ Parameters } & SASW & SASEF \\
\hline $\mathrm{pH}$ & 8.25 & 1.43 \\
Conductivity $/ \mathrm{mS} \mathrm{cm}^{-1}$ & 2.23 & 17.66 \\
\hline Turbidity / NTU & \multicolumn{2}{|c}{89.6} \\
COD / $\mathrm{mg} \mathrm{dm}^{-3}$ & \multicolumn{2}{|c}{23500} \\
PHE $/ \mathrm{mg} \mathrm{dm}^{-3}$ & \multicolumn{2}{|c}{35} \\
\hline
\end{tabular}



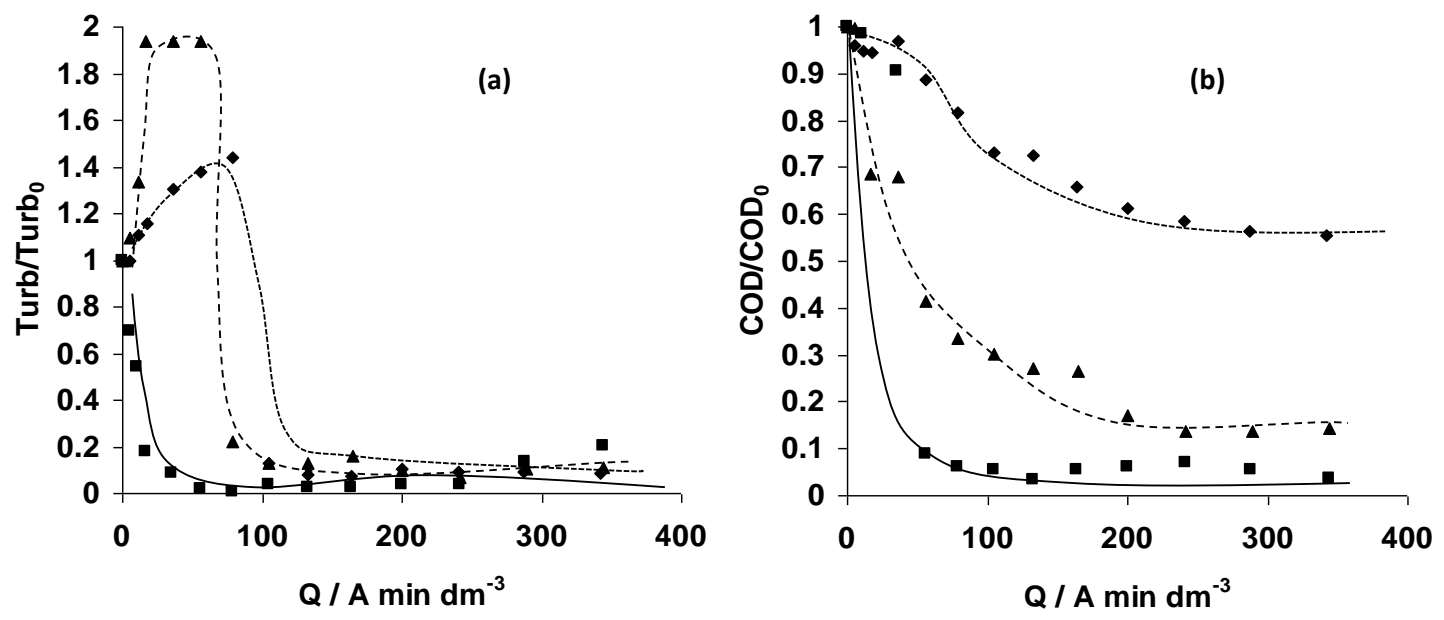

Figure 1 


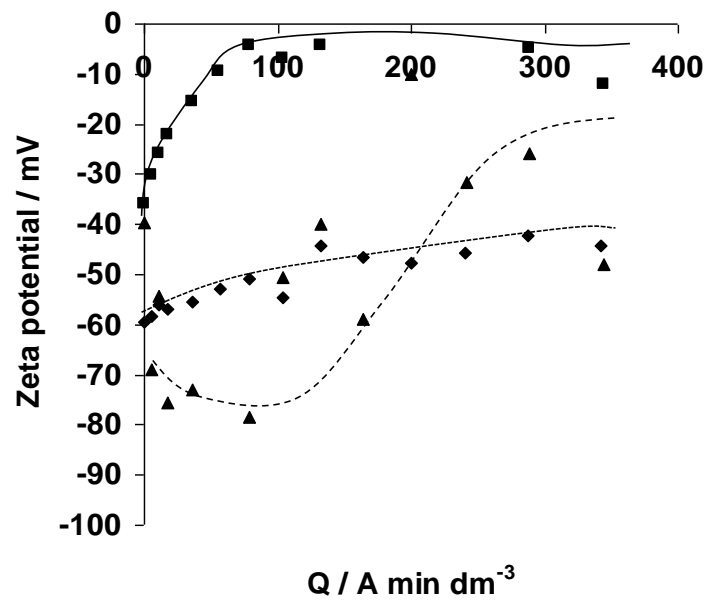

Figure 2 

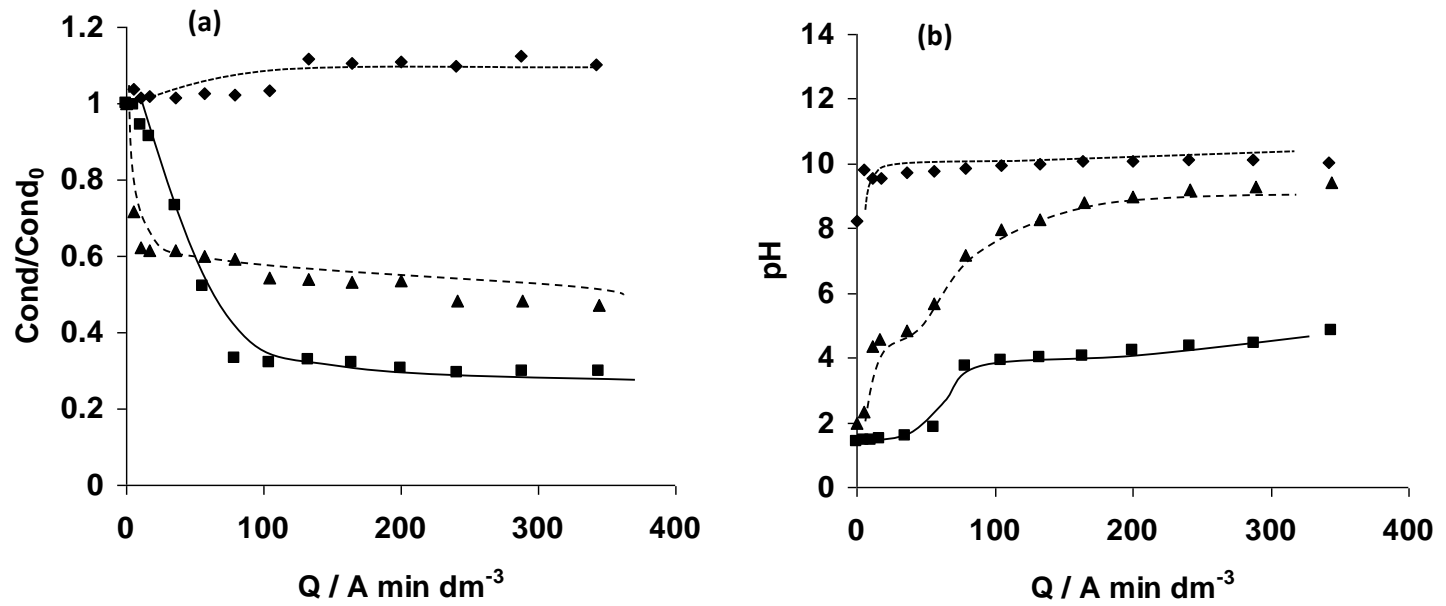

Figure 3 


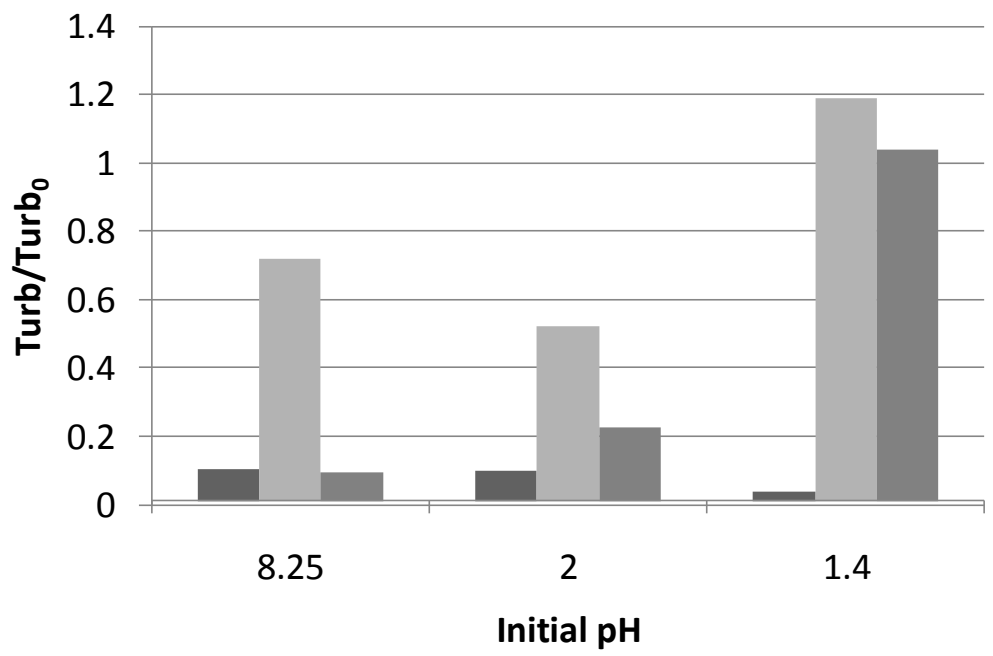

Figure 4 


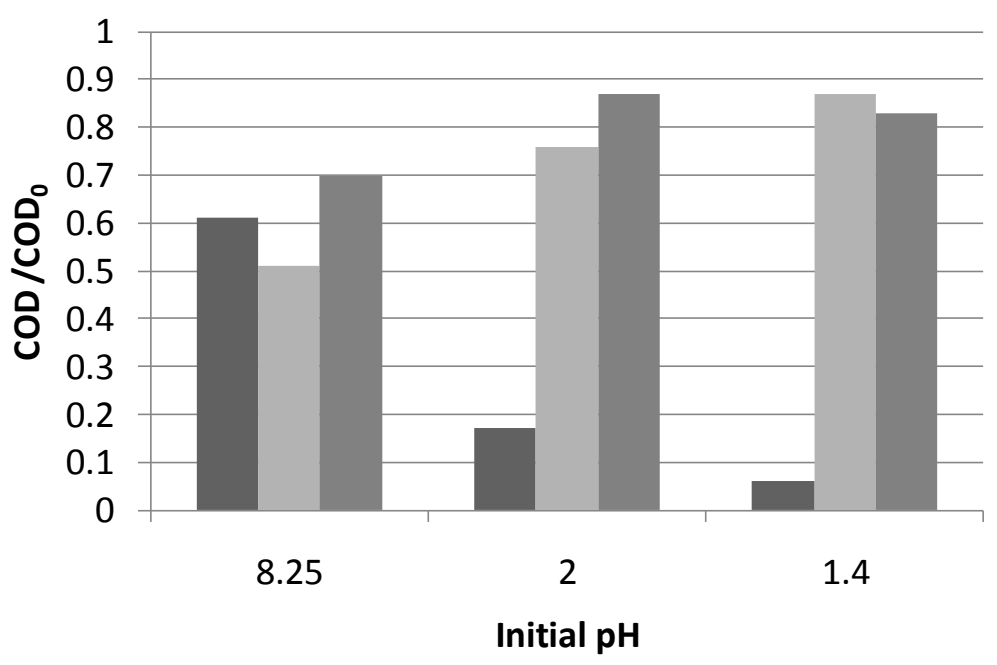

Figure 5 


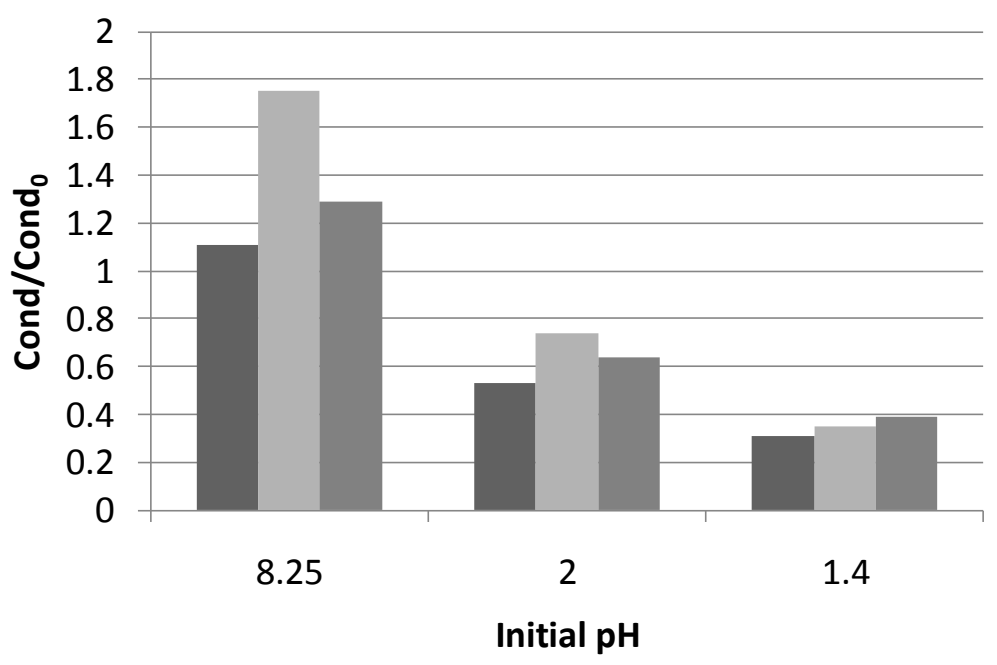

Figure 6 


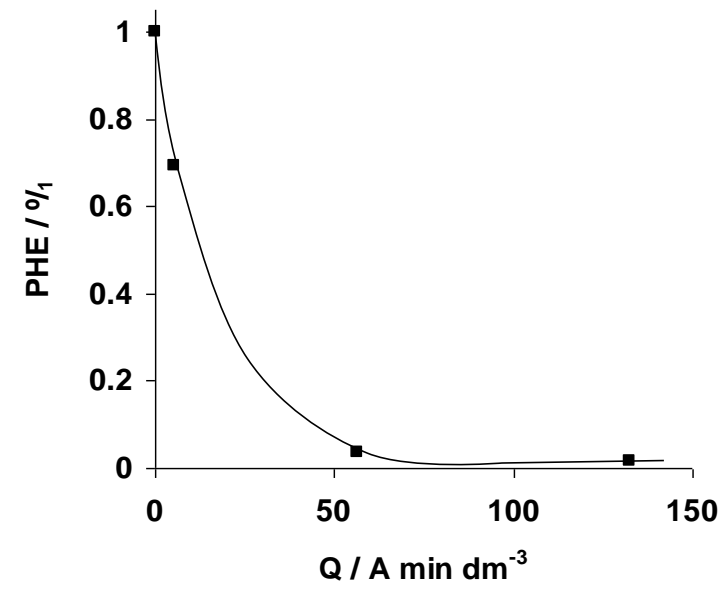

Figure 7 


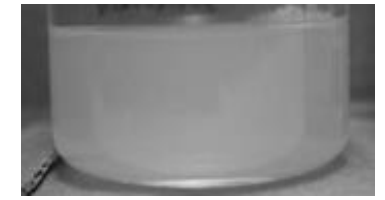

(a)

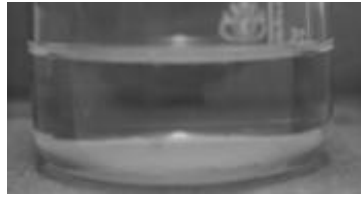

(b)

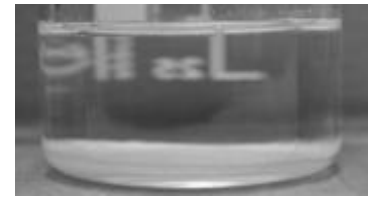

(c)

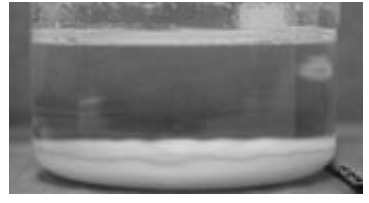

(d)

Figure 8 